\title{
HURRICANE IKE (2008) NEARSHORE WAVES: SIMULATIONS AND MEASUREMENTS
}

\author{
Christopher Bender ${ }^{1}$, Ph.D., Jane McKee Smith², Ph.D., and Andrew Kennedy ${ }^{3}$, Ph.D.
}

\begin{abstract}
Hurricane Ike (2008) caused extensive damage and many deaths across portions of the Caribbean and along the coasts of Texas and Louisiana. After reaching peak intensity over the open waters of the Atlantic Ocean, Hurricane Ike, with its associated storm surge, then caused extensive damage across parts of the northwestern Gulf Coast when it made landfall in the late hours of September 12th along the upper Texas coast at the upper end of Category 2 intensity. An extensive instrumentation effort allowed the collection of both nearshore and inland wave and water level data as Hurricane Ike passed by the Louisiana and Texas coasts. This paper presents the results of a validation effort for the STWAVE model and the bottom friction coefficients applied in the model with comparisons to the Hurricane Ike measured wave data. STWAVE model results indicate good agreement with the measured nearshore wave data for an open water Manning ' $n$ ' bottom friction coefficient equal to $0.03 \mathrm{~s} / \mathrm{m}^{0.33}$. STWAVE model results indicate good agreement with the measured inshore wave data with Manning ' $n$ ' bottom friction coefficients equal to values derived from land classification data and applied in the ADCIRC model.
\end{abstract}

Keywords: nearshore waves, hurricanes, wave measurement, bottom friction

\section{INTRODUCTION}

Hurricane Ike was a long-lived Cape Verde hurricane that caused extensive damage and many deaths across portions of the Caribbean and along the coasts of Texas and Louisiana (NHC, 2010). The storm reached its peak intensity as a Category 4 hurricane (on the Saffir-Simpson Hurricane Scale) over the open waters of the central Atlantic, directly impacting the Turks and Caicos Islands and Great Inagua Island in the southeastern Bahamas before affecting much of the island of Cuba (NHC, 2010). Hurricane Ike, with its associated storm surge, then caused extensive damage across parts of the northwestern Gulf Coast when it made landfall in the late hours of September 12th along the upper Texas coast at the upper end of Category 2 intensity (NHC, 2010).

An extensive instrumentation effort allowed the collection of both nearshore and inland wave and water level data as Hurricane Ike passed by the Louisiana and Texas coasts. These data provide the basis for the effort contained in this paper to simulate Hurricane Ike's nearshore waves with the STWAVE spectral wave model (Smith et al., 2001; Smith and Sherlock, 2007). A modeling system coupled the STWAVE model with surge and wind data from the ADCIRC hydrodynamic model (Luettich and Westerink, 2004) and offshore wave spectra from the WAM model (Komen et al., 1994). A validation effort compared the Hurricane Ike measured wave data with the STWAVE model results. Modification of the STWAVE bottom friction coefficients allowed examination of the effect of bottom friction on the STWAVE results.

\section{WAVE DATA COLLECTION}

A lack of nearshore and inland measured wave data for Hurricane Katrina (2005) limited the ability to validate nearshore wave models for the storm. As Hurricane Ike approached the Texas coast, efforts to deploy nearshore and inland instruments capable of measuring short waves (periods less than 20 seconds) provided valuable data on wave conditions during Hurricane Ike and in the days preceding and following the storm. This section focuses on the nearshore and inland wave measurement efforts of Dr. Andrew Kennedy (Univ. of Notre Dame) and the United States Geological Survey (USGS). Several National Oceanic and Atmospheric Administration (NOAA) National Data Buoy Center (NDBC) stations collected mostly offshore wave data during Hurricane Ike.

\section{Nearshore Data Collection}

Dr. Andrew Kennedy has developed rapidly-deployable pressure sensing instruments suitable for measuring storm wave conditions for relatively short durations (one to two weeks) in nearshore environments - 20 to 40 foot (ft) water depth. Major advantages of the instruments include the deployment and retrieval procedures that allow for rapid installation in the days before large tropical systems make landfall; thus allowing placement based on storm track information that reasonably constrains the landfall location. The functionality of the instruments has been demonstrated in the

\footnotetext{
${ }^{1}$ Taylor Engineering, Inc 10510 Deerwood Park Blvd, Bldg 300, Suite 300, Jacksonville, FL, 32259, USA

${ }^{2}$ Engineer Research and Development Center, Coastal and Hydraulics Laboratory, Vicksburg, MS, 39180, USA

${ }^{3}$ University of Notre Dame, Dept. of Civil Engineering and Geological Sciences, South Bend, IN, 46556, USA
} 
nearshore wave measurements captured during six storm deployments including Hurricanes Gustav in 2008 (20 instruments deployed, see Kennedy et al., 2010a). These deployments use $1 \mathrm{~Hz}$ pressure measurements, helicopter deployment, and boat and diver retrieval to measure waves and surge over hundreds of miles of coastline

Before Hurricane Ike made landfall in Texas, Dr. Kennedy and his team deployed nine instruments along the Texas coast from Corpus Christi to the Texas/Louisiana border. The deployment operation placed the instruments in approximately $30 \mathrm{ft}$ water depth. Table 1 provides details of the instrument locations and Figure 1 plots the positions along the Texas coast for the easternmost seven instruments that returned usable data records. The data provided nearshore wave measurements required to validate the STWAVE Hurricane Ike simulations. The figure contours represent the depth of the ADCIRC mesh applied to develop the STWAVE grid bathymetry and topography. Figure 1 also presents the approximate track of Hurricane Ike (2008) and the inland limit of the ADCIRC mesh. Analysis and filtering of the raw pressure data allowed development of water level, wave spectra, and wave height estimates. The STWAVE Results and Discussion section presents the measured wave data collected by Dr. Kennedy during Hurricane Ike with comparisons to the STWAVE simulations.

\begin{tabular}{|c|c|c|c|c|c|c|}
\hline \multirow{2}{*}{ Station } & \multicolumn{2}{|c|}{ Latitude } & \multicolumn{2}{|c|}{ Longitude } & \multirow{2}{*}{ Status } & \multirow{2}{*}{$\frac{\text { Approx. Depth }}{(\mathrm{ft})}$} \\
\hline & (deg) & $(\min )$ & (deg) & $(\min )$ & & \\
\hline $\mathrm{R}$ & 27 & 37.734 & 97 & 7.056 & OK & 52.2 \\
\hline$S$ & 28 & 12.464 & 96 & 33.022 & OK & 41.2 \\
\hline$T$ & 28 & 26.083 & 96 & 12.842 & Lost & - \\
\hline$U$ & 28 & 37.503 & 95 & 45.141 & OK & 46.4 \\
\hline $\mathrm{V}$ & 28 & 52.224 & 95 & 18.907 & $\mathrm{OK}$ & 41.8 \\
\hline W & 29 & 4.284 & 95 & 2.375 & OK & 42.8 \\
\hline$x$ & 29 & 16.876 & 94 & 42.537 & OK & 31.3 \\
\hline$Y$ & 29 & 29.786 & 94 & 23.304 & OK & 28.7 \\
\hline Z & 29 & 35.081 & 94 & 7.520 & OK & 31.1 \\
\hline
\end{tabular}

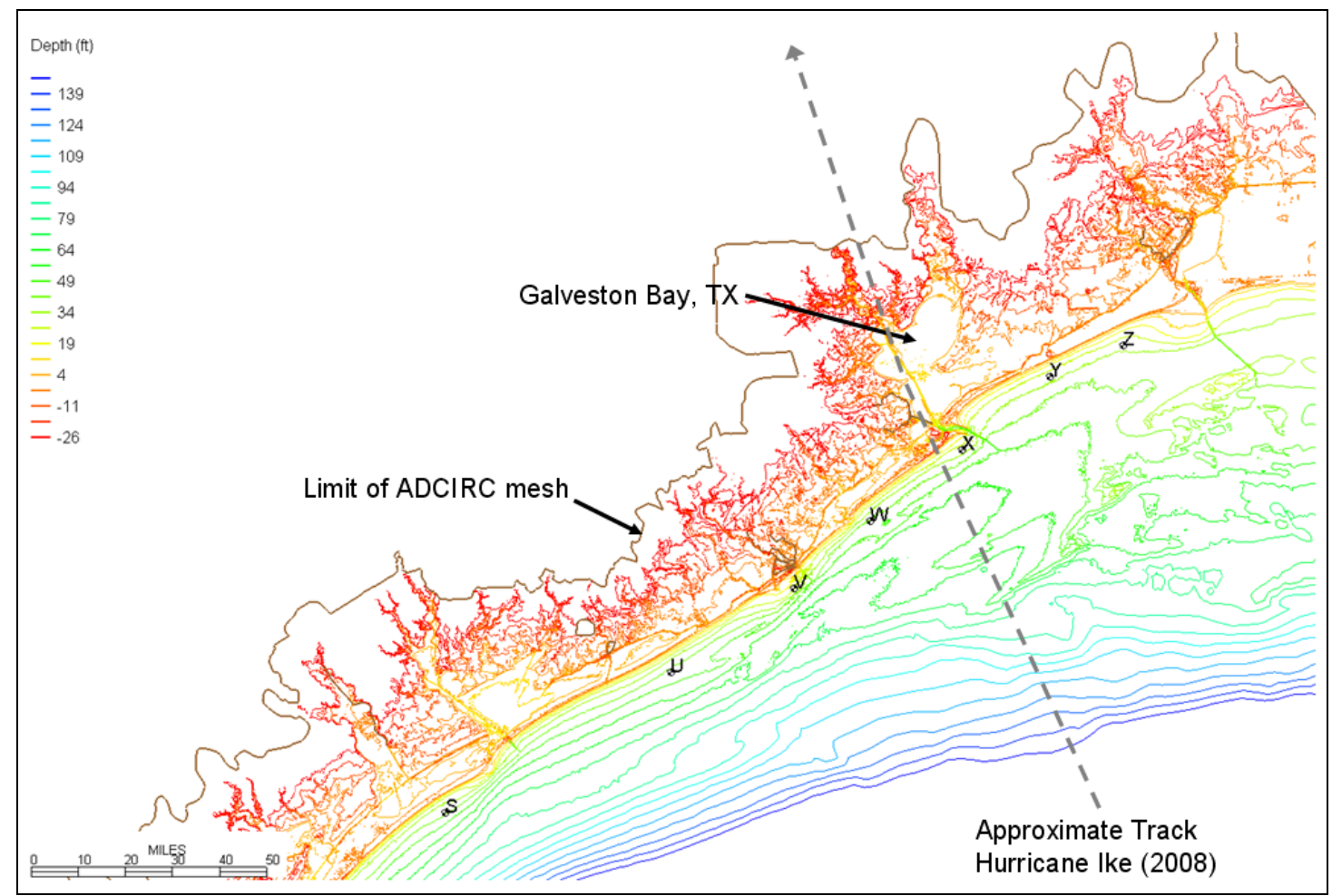

Figure 1. Locations of Nearshore (Kennedy Stations) Wave Measurements During Hurricane Ike (2008) 


\section{Inland Data Collection}

The USGS deployed a temporary monitoring network of 117 pressure transducers (sensors) at 65 sites over an area of about 5,000 square miles to record the timing, areal extent, and magnitude of inland hurricane storm surge generated by Hurricane Ike (East, et al., 2008). The USGS classified eight of the stations as "beach/wave" stations. The beach/wave stations featured locations and sampling frequencies that allowed some level of estimation of inland wave height — for analysis details see Kennedy et al. (2010b). Table 2 provides details of the USGS beach/wave stations and Figure 2 plots the positions along the Texas coast. The two easternmost stations in Jefferson County occur relatively close to each other. The STWAVE Results and Discussion section presents the measured inland wave data collected by the UGSG during Hurricane Ike with comparisons to the STWAVE simulations.

\begin{tabular}{|c|c|c|c|}
\hline \multirow{2}{*}{ Station } & Lat & Long & Elevation \\
\hline & (deg) & (deg) & (ft-NAVD) \\
\hline Gal-001 & 29.4514 & 94.6342 & 7.95 \\
\hline Gal-008 & 29.3344 & 94.7511 & 4.30 \\
\hline Gal-010 & 29.2381 & 94.8778 & 4.42 \\
\hline Gal-015 & 29.0861 & 95.1172 & 0.60 \\
\hline Mat-005 & 28.6006 & 95.9781 & 1.31 \\
\hline Mat-008 & 28.7642 & 95.6269 & 7.48 \\
\hline Jef-002 & 29.6750 & 94.0436 & 5.87 \\
\hline Jef-009 & 29.6627 & 94.0884 & 0.50 \\
\hline
\end{tabular}

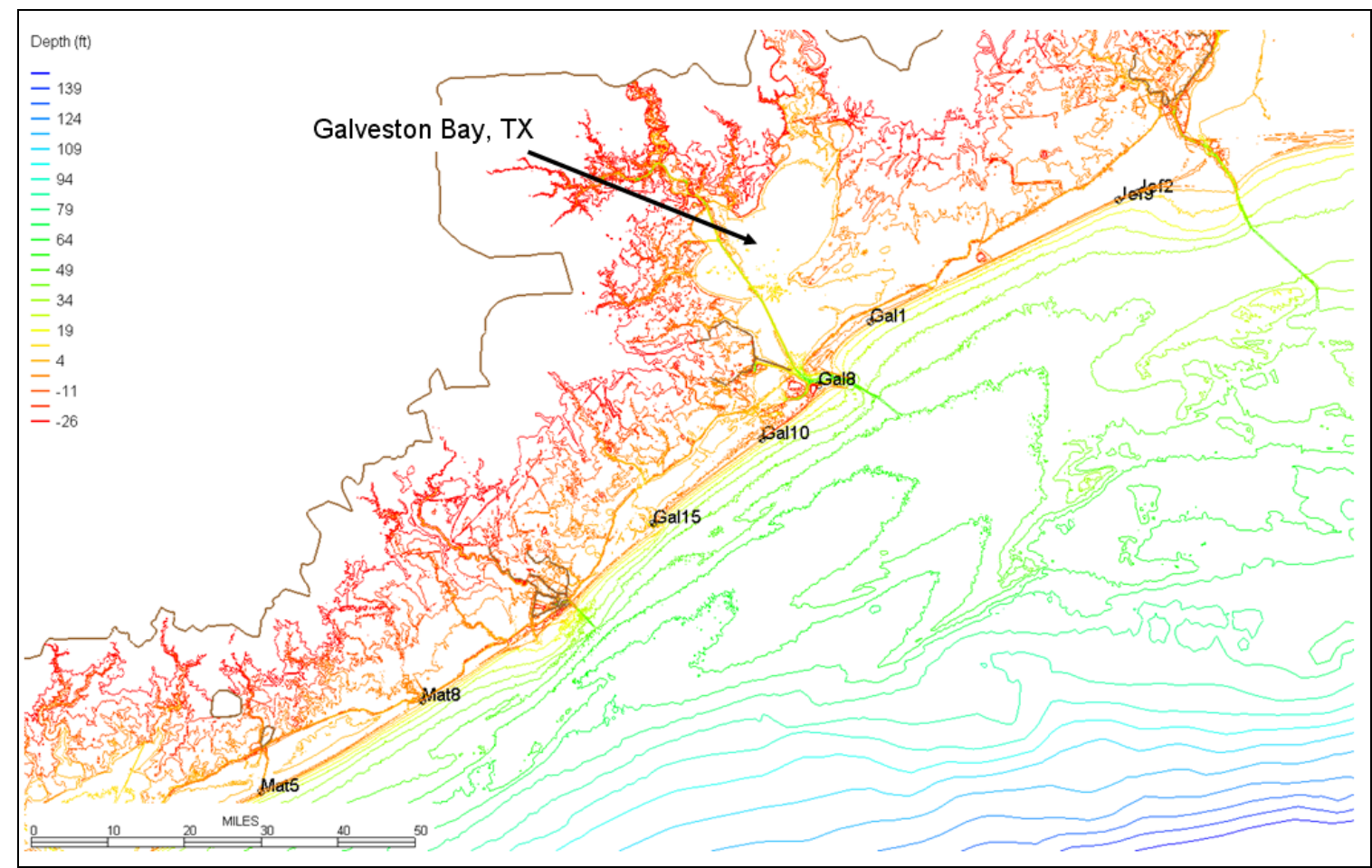

Figure 2. Locations of Inland (USGS Stations) Wave Measurements During Hurricane Ike (2008)

\section{STWAVE MODEL AND INPUT DATA}

\section{STWAVE Model Description}

The numerical model STWAVE was applied to generate and transform nearshore waves for the Texas Joint Storm Surge (JSS) Study. Notably, the application of STWAVE to develop the nearshore waves follows closely the methods developed for the Interagency Performance Evaluation Taskforce 
(IPET) report (USACE, 2006) and the Louisiana JSS Study conducted from 2006 to 2009. STWAVE numerically solves the steady-state conservation of spectral action balance along backward-traced wave rays:

$$
\left(C_{g a}\right)_{x} \frac{\partial}{\partial x} \frac{C_{a} C_{g a} \cos (\mu-\alpha) E(f, \alpha)}{\omega_{r}}+\left(C_{g a}\right)_{y} \frac{\partial}{\partial y} \frac{C_{a} C_{g a} \cos (\mu-\alpha) E(f, \alpha)}{\omega_{r}}=\sum \frac{S}{\omega_{r}}
$$

where $C_{g a}$ equals absolute wave group celerity, $x, y$ are the spatial coordinates, subscripts indicate $x$ and $y$ components, $C_{a}$ equals absolute wave celerity, $\mu$ equals current direction, $\alpha$ equals propagation direction of a spectral component, $E$ equals spectral energy density, $f$ equals frequency of a spectral component, $\omega_{r}$ equals relative angular frequency (frequency relative to the current), and $S$ represents energy source/sink terms.

The source terms include wind input, nonlinear wave-wave interactions, dissipation within the wave field, and surf-zone breaking. The terms on the left-hand side of Equation 1 represent wave propagation (refraction and shoaling), and the source terms on the right-hand side of the equation represent energy growth and decay in the spectrum. The assumptions made in STWAVE include mild bottom slope and negligible wave reflection; steady waves, currents, and winds; linear refraction and shoaling; and depth-uniform current.

STWAVE implementation can occur as either a half-plane model - the model only represents waves propagating toward the coast — or a full-plane model that allows wave generation and propagation in all directions. STWAVE, a finite-difference model, calculates wave spectra on a rectangular grid. The model outputs zero-moment wave height $\left(\mathrm{H}_{\mathrm{mo}}\right)$, peak or mean $\left(\mathrm{T}_{\mathrm{mm} 1}\right)$ wave period $\left(T_{p}\right.$ or $\left.T_{m}\right)$, and mean wave direction $\left(\alpha_{m}\right)$ at all grid points and two-dimensional spectra at selected grid points. Recent upgrades to STWAVE include an option to input spatially variable wind, surge, and bottom friction coefficient fields. The surge significantly alters the wave transformation and generation for the hurricane simulations in shallow areas and flooded low-lying areas. STWAVE can account for the wave energy dissipation (sink of energy, E) from bottom friction with either a JONSWAP or Manning ' $n$ ' formulation. The Hurricane Ike simulations applied the Manning ' $n$ ' formulation to remain consistent with work completed for the LA JSS and IPET studies and to leverage the available land cover and Manning ' $\mathrm{n}$ ' values for inundated inland areas where STWAVE simulates waves at times of peak storm surge. The Manning ' $n$ ' friction formulation applies the equation of Holthuijsen (2007):

$$
S_{b f}=\frac{-1}{g}\left(\frac{g n^{2}}{d^{1 / 3}}\right) \frac{\sigma^{2}}{\sinh ^{2} k d} E(f, \alpha) u_{r m s}
$$

where $d$ equals depth, $n$ equals the Manning's coefficient, $\sigma$ equals the wave angular frequency, $k$ equals the wave number, and $u_{r m s}$ equals the root-mean-square velocity near the bottom.

\section{Nearshore Wave Modeling Method}

The Hurricane Ike simulations applied five STWAVE grids for the Texas project area: Northeast (NE), Central (CE), Southwest (SW), Northeast_nest (NEn), and Central_nest (CEn) — Figure 3. Three large grids (NE, CE, SW) with offshore boundaries at depths near $100 \mathrm{ft}(30 \mathrm{~m})$ encompassed the entire coast of Texas and applied the efficient half-plane version of STWAVE (which must approximately align with the shoreline). Two nested grids (NEn and CEn) covered Galveston Bay and Corpus Christi Bay and applied the full-plane version of STWAVE to allow generation of wind waves in all directions. Notably, memory requirements for the full-plane model (at the time of the study) precluded its use for the large grids with offshore boundaries. The input for each grid includes the bathymetry (interpolated from the ADCIRC domain), surge fields (interpolated from ADCIRC surge fields), and wind fields (interpolated from the ADCIRC wind fields, which apply land effects to the base wind fields). The wind, surge, and boundary spectra applied in STWAVE featured spatial and temporal - 30 minute time intervals - variation for all grids. 


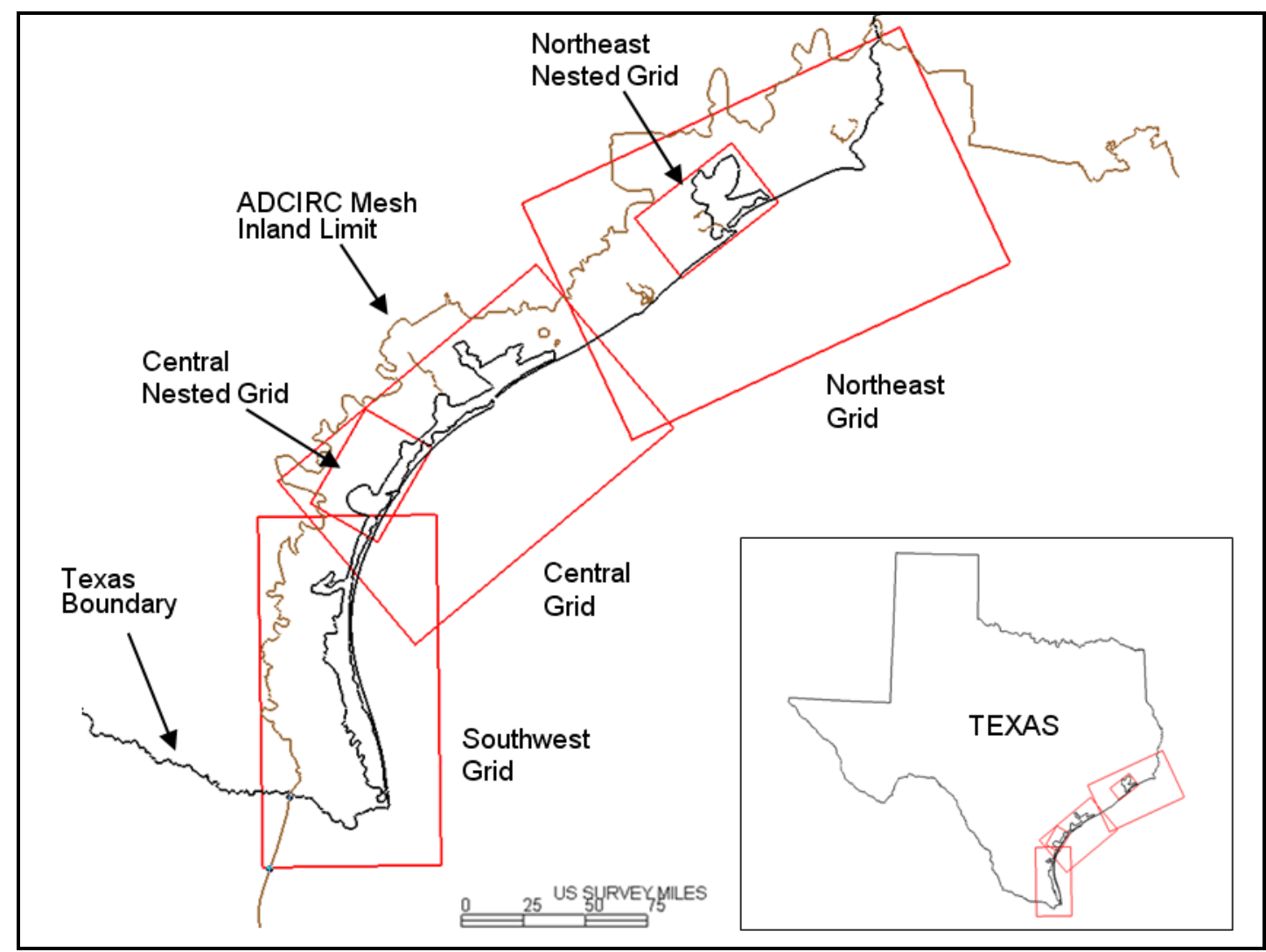

Figure 3. STWAVE Grids Applied During Hurricane Ike (2008) and Texas Storm Surge Study Simulations

A Fortran code applied a weighted averaging technique to interpolate the bathymetry and topography data from the ADCIRC grid to the individual STWAVE grids. Three overlapping grids NE, CE, and SW - covered the nearshore coastal areas for the entire coast of Texas at a resolution of 656 feet (200 meters). The NE, CE, and SW grids featured offshore boundaries near 100 feet with the coverage area extending from approximately 36 miles east of the Texas Louisiana border to approximately 31 miles south of the border with Mexico. The half-plane simulations are forced with both the local winds interpolated from ADCIRC and the wave spectra interpolated on the offshore boundary from the regional WAM model.

The NEn and CEn nested grids encompass Galveston Bay and Corpus Christi Bay at a resolution of 656 feet. The nested grids receive wave spectra information from the NE and CE half-plane grids at 100 locations along the offshore boundary — and apply the full-plane STWAVE model to include generation and transformation along the entire bay shoreline. These full-plane simulations are forced with both the local winds interpolated from ADCIRC and the wave spectra interpolated on the offshore boundary from the half-plane NE and CE STWAVE models.

\section{Input Data Description}

The STWAVE grids applied bathymetry and topography interpolated from the ADCIRC grid. The ADCIRC grid applied the best available and most recent Lidar data to represent the Texas coastline topography and the best available and most recent soundings and survey data to represent the Texas coastline bathymetry. The study grids applied topography created from post-Hurricane Ike Lidar to capture the dune erosion that occurred during the storm.

Oceanweather, Inc. (OWI) developed the wind and pressure fields for the Hurricane Ike simulations with an optimum combination of Planetary Boundary Layer (PBL) modeling (Thompson and Cardone, 1996) for pressures and kinematic analyses provided by HWnd (Powell 1998, et. al) for winds. The Hurricane Research Division (HRD) developed HWnd marine surface wind analyses for periods during and just before landfall. OWI blended all snapshots (HWnd and PBL) into a synoptic scale wind field using a blend of manual kinematic analysis and the IOKA (Interactive Kinematic Analysis) system (Cox et. al 1995). 
The STWAVE models apply wind fields (variable in space) interpolated onto the STWAVE grids from the ADCIRC model. Within the ACIRC model, a Lagrangian interpolation develops wind field estimates between the original OWI 15-minute snaps. Additionally, ADCIRC adjusts the OWI winds from 30-min average to 10-min average wind speeds and applies an anisotropic wind sheltering parameter to locally reduce the winds where appropriate. The wind sheltering procedure applies a 12direction nodal value that accounts for wind shielding due to trees, buildings, etc. The wind sheltering may reduce nodal wind speeds depending upon land cover up to several miles upwind. In addition, ADCIRC also applies a canopy parameter that locally zeros out the wind speed for ADCIRC node with substantial tree canopy coverage. The National Land Cover Data (NLCD) set provides the data necessary to develop both the wind-sheltering and tree canopy parameters.

The offshore wave model WAM provided the wave spectra applied by the STWAVE models at the offshore model boundary. A Fortran code interpolated the full-plane WAM model results to the half-plane model convention for each STWAVE half-plane model grid - NE, CE, and SW. The Fortran code also selected the appropriate time interval for the WAM results to ensure proper synchronization between the input wave spectra and the input wind and water level data.

In addition to the wind data, ADCIRC supplies water level data (with 30 minute time steps) to the STWAVE models. Fortran codes interpolated the ADCIRC model data from the ADCIRC mesh to individual surge and wind files for each the five STWAVE models. Each surge and wind file contains data for 157 different time steps. The timing of the input provides approximately 54 hours of wind and surge data prior to landfall and 24 hours of input after landfall. The ADCIRC model produces significant inland surge that reaches high elevations over a significant inland inundation area. The STWAVE model updates the model domain to allow for wave development and propagation over these flooded inland areas.

\section{STWAVE RESULTS AND DISCUSSION}

The bottom friction coefficient applied within the STWAVE model provides the only 'tuning' or calibration coefficient for the model. In addition to a no bottom friction setting, STWAVE model user's can select either a JONSWAP or Manning ' $n$ ' formulation for the bottom friction with either a spatially constant or spatially variable bottom friction coefficient. A recent addition to the STWAVE model, bottom friction allows STWAVE model calibration and validation through selection of site specific bottom friction coefficients.

The Hurricane Ike analysis applied the Manning ' $n$ ' bottom friction formulation with several different bottom friction coefficient values and compared the model results to available measured wave data in the nearshore and inland areas. The Louisiana JSS and IPET analyses applied the Manning ' $n$ ' formulation within STWAVE and the TX JSS continued with that formulation to ensure consistency. However, the available Hurricane Ike measured nearshore and inland wave data allowed the TX JSS to evaluate the Manning ' $n$ ' coefficients within the STWAVE model that provided the best match with the measurements. Lack of measured nearshore and inland wave data in coastal Louisiana during hurricane conditions precluded the LA JSS and IPET studies from detailed investigations of the bottom friction coefficients within the STWAVE model.

The United States Geological Survey (USGS) National Land Cover Database (NLCD) provided the land cover type classifications in overland regions necessary to develop hydraulic bottom roughness (Manning ' $\mathrm{n}$ ' value) for the ADCIRC model. Standard hydraulic literature (Chow, 1959; Henderson, 1966; Arcement and Schneider, 1989; Barnes, 1967) provided the Manning ' $n$ ' associated with each land cover type - with values selected, interpolated, or extrapolated as necessary. The standard STWAVE (STW_ADCIRC_n) simulation applied Manning ' $n$ ' bottom friction coefficients interpolated directly from the ADCIRC mesh onto each STWAVE grid. Notably, the open water Manning ' $n$ ' applied for LA JSS equaled $0.02 \mathrm{~s} / \mathrm{m}^{0.33}$. However, an ADCIRC analysis for the TX JSS found that an open water ' $n$ ' value of $0.012 \mathrm{~s} / \mathrm{m}^{0.33}$ allowed currents on the TX nearshore shelf to develop and provide a better representation of hurricane surge before the peak storm surge.

Besides the STW ADCIRC n simulation, other STWAVE simulations applied either constant or varying bottom friction coefficient Manning ' $n$ ' settings to best match the available nearshore and inland wave data. The remainder of this section presents results of the STWAVE with model output viewed as contour plots of maximum wave parameters, time series of wave parameters, or scatter plots of measured versus simulated wave parameters. Wave parameters examined include significant wave height (calculated as $\mathrm{H}_{\mathrm{mo}}$ ), peak water period, mean wave period (calculated as $\mathrm{T}_{\mathrm{mm}}$ ) and mean wave direction. 
Figure 4 presents the maximum wave height observed in the NEn STWAVE grid for the STW_ADCIRC_n simulation of Hurricane Ike. A full-plane STWAVE simulation, the NEn grid vectors in Figure 4.3 indicate mean wave direction at the time of maximum wave conditions in both onshore and offshore directions. Notably, the maximum wave conditions in Figure 4 can occur at different times during the simulation. The NEn grid features wave heights in excess of $25 \mathrm{ft}$ near the grid offshore boundary and wave heights near $10 \mathrm{ft}$ in some parts of NE Galveston Bay. Along the western shoreline of Galveston Bay, maximum waves move southwest with heights near $8 \mathrm{ft}$. Maximum wave heights over some inundated inland areas reach 4 to $7 \mathrm{ft}$. Review of the wave periods in the NEn at the time of maximum wave height indicates mean wave periods from 10 to 12 seconds offshore, and from 5 to 8 seconds in Galveston Bay and over inundated inland areas.

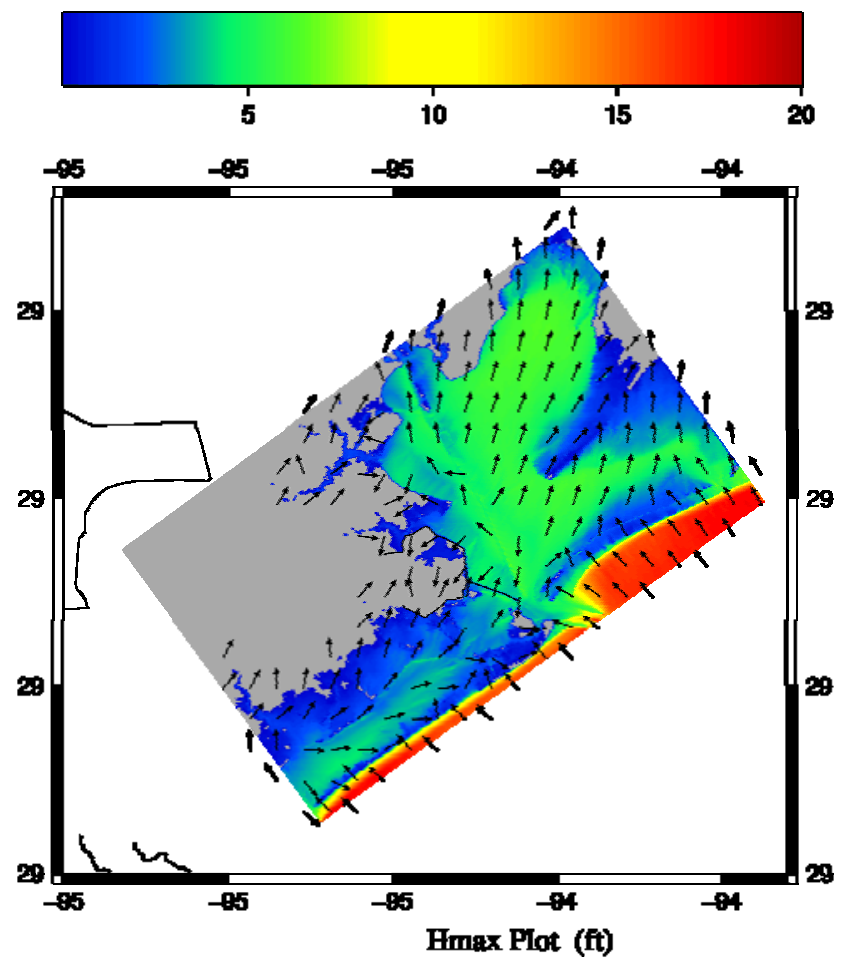

Figure 4. Contour Plot of Maximum Wave Heights from NEnest Grid STWAVE Simulation of Hurricane Ike (2008)

Figures 5 and 6 present the time series of simulated and measured wave height and peak wave period at Kennedy Station Z. For reference, the eye of Hurricane Ike moved approximately between Station's X and Y in the late hours of September 12 and early hours of September 13 (shown as day 257 in time series plots). Figure 5 shows a peak measured wave height of $18.3 \mathrm{ft}$ at Kennedy Station Z, the second largest measured at any Kennedy station. The STW_ADCIRC_n simulation over-predicts the wave height consistently as the storm passes — in some cases, the over-prediction exceeds $5 \mathrm{ft}$ or $50 \%$ of the measured wave height. The STW_NoFric simulation results indicate even higher wave heights than the STW_ADCIRC_n simulation - an expected result — and show the influence of bottom friction dissipation on the wave height as the storm passes. With the exception of the initial simulation hours, the STW_Floor0.03 results show good agreement with the measured data during the entire time series and a peak value that nearly matches the measured peak value. The STW_Floor0.03 models applied a minimum Manning ' $n$ ' value equal to $0.03 \mathrm{~s} / \mathrm{m}^{0.33}$ — this approach mainly raised the bottom friction coefficient in open water areas from $0.012 \mathrm{~s} / \mathrm{m}^{0.33}$ to $0.03 \mathrm{~s} / \mathrm{m}^{0.33}$. The peak period results (Figure 6) show good agreement between the measured and simulated peak wave periods. The results indicate very little variation in the STWAVE peak wave period for the STW_ADCIRC_n, STW_NoFric, and STW_Floor0.03 simulations. 


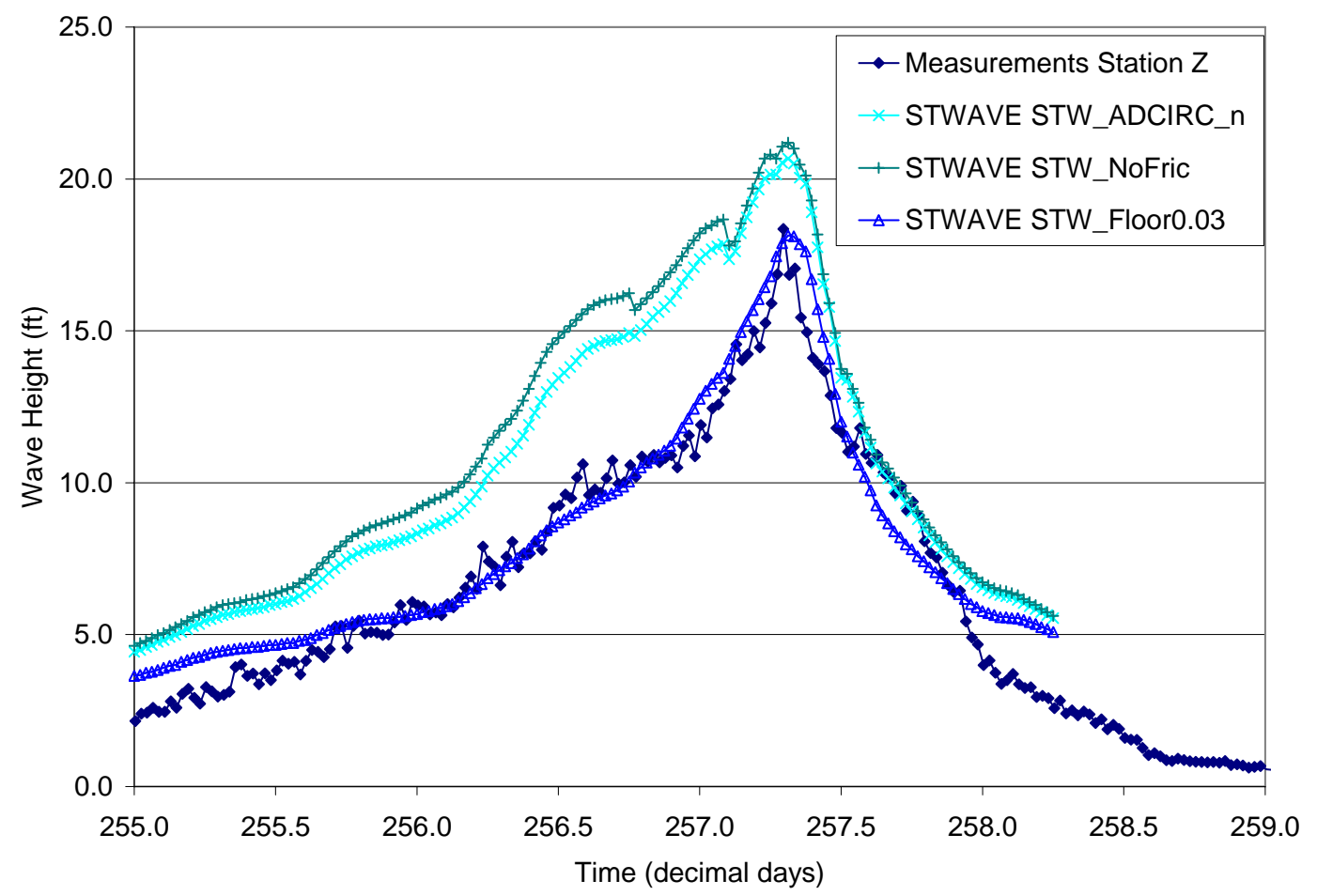

Figure 5. Time Series of STWAVE Simulated Wave Heights and Measured Waves at Kennedy Station Z During Hurricane Ike (2008)

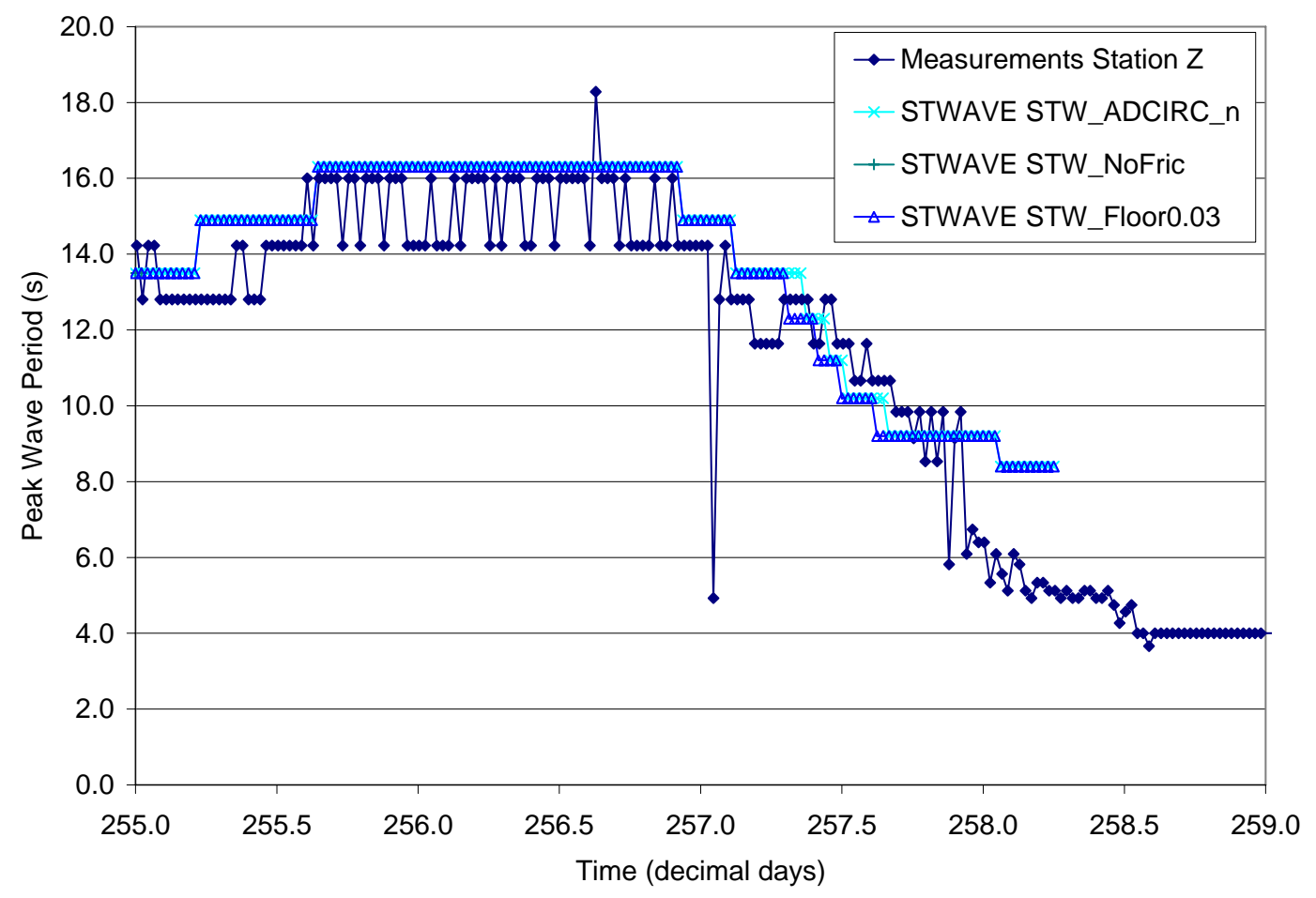

Figure 6. Time Series of STWAVE Simulated Peak Wave Periods and Measured Waves at Kennedy Station Z During Hurricane Ike (2008) 
The USGS stations occur in inland areas with different elevations that the storm inundated at different times. Importantly, the STWAVE model will only develop waves in inland areas after they flood (surge in ADCIRC exceeds local elevation) so the comparison of the simulated and measured wave heights requires reasonable surge predictions from ADCIRC. For shallow water conditions that exhibit depth-limited breaking, correct prediction of the water depth proves critical to accurate prediction of the waves. Review of simulated surge conditions shows good prediction at the USGS stations, but the timing and magnitude of the measured and modeled surge show some difference.

The relatively low sampling frequency of the USGS stations increases the uncertainty in the estimates of measured wave heights and does not allow for evaluation of accurate wave period information. However, the capability to extract any measured inland wave estimates (even with increased uncertainty) provides a useful data set to compare the simulated inland STWAVE results. Notably, differences in elevation at the USGS stations and elevation in the STWAVE grids, and uncertainty in the overland conditions between the shoreline and USGS stations present two other factors that can cause differences in the measured and simulated wave conditions. Despite these limitations, the comparisons provide a means to evaluate the general model performance for the simulation of waves in inundated inland areas during Hurricane Ike.

Figure 7 presents the time series of simulated and measured wave height at USGS Station Jef-002. The USGS placed Station Jef-002 at an elevation of approximately $5.9 \mathrm{ft}-\mathrm{NAVD}$ and the STWAVE grid exhibits an elevation of $4.3 \mathrm{ft}-\mathrm{NAVD}$ at this location. For reference, the eye of Hurricane Ike moved east of Station Gal-001 in the late hours of September 12 and early hours of September 13 (shown as day 257 in time series plots). Figure 7 shows a peak measured wave height of $4.7 \mathrm{ft}$, the third largest height measured at any USGS Station. The STW_ADCIRC_n and STW_Floor0.03 simulations show matching results with initial wave heights occurring about seven hours after the measured wave heights begin. The STW_ADCIRC_n and STW_Floor0.03 simulations over-predict the wave height consistently as the storm passes with simulated peak conditions approximately $2.5 \mathrm{ft}$ greater than measured conditions. The STW_ADCIRC_n and STW_Floor0.03 simulations have identical Manning ' $n$ ' values at Station Jef-002. The matching STWAVE wave height results at the station suggest that depth-limited breaking in the inland areas removes any differences in wave height that developed in open water areas where the two models apply different bottom friction coefficients.

Figure 8 presents the time series of simulated and measured wave height at USGS Station Gal001. The USGS placed Station Gal-001 at an elevation of approximately $8.0 \mathrm{ft}-\mathrm{NAVD}$; the STWAVE grid exhibits an elevation of $6.0 \mathrm{ft}-\mathrm{NAVD}$. Figure 8 shows a peak measured wave height of $5.8 \mathrm{ft}$, the second largest measured at any USGS Station. The STW_ADCIRC_n simulation initial wave heights occur approximately 12 hours after the measured wave heights begin. The STW_ADCIRC_n simulation initially under-predicts, then over-predicts the wave height through peak conditions with simulated peak conditions approximately $1.5 \mathrm{ft}$ less than the measured waves. The STW_Floor0.03 results indicate no delay in the time of initial wave development and matching wave heights as compared to the STW_ADCIRC_n simulation.

Overall, the STWAVE simulations provide reasonable estimates of wave height and period as Hurricane Ike approaches and passes the Texas coast. Scatter plots of measured and simulated wave heights at the Kennedy nearshore and USGS inland stations provide an additional means to view the model performance and evaluate the influence of the bottom friction settings in the STWAVE models. Figure 9 presents a scatter plot of measured and simulated peak wave heights for the STW_ADCIRC_n and STW_Floor0.03 simulations. Figure 9 highlights the influence of the STWAVE friction setting on the maximum wave conditions at the Kennedy nearshore stations with the STW_ADCIRC_n results over-predicting the waves and the STW_Floor0.03 results showing much improved agreement with the measured peak waves. At the USGS inland stations, the STW_ADCIRC_n and STWAVE_Floor0.03 models produce identical results. Based on the time series results and the scatter plot, STW_Floor0.03 provides the best agreement with the measured data at the measurement stations. 


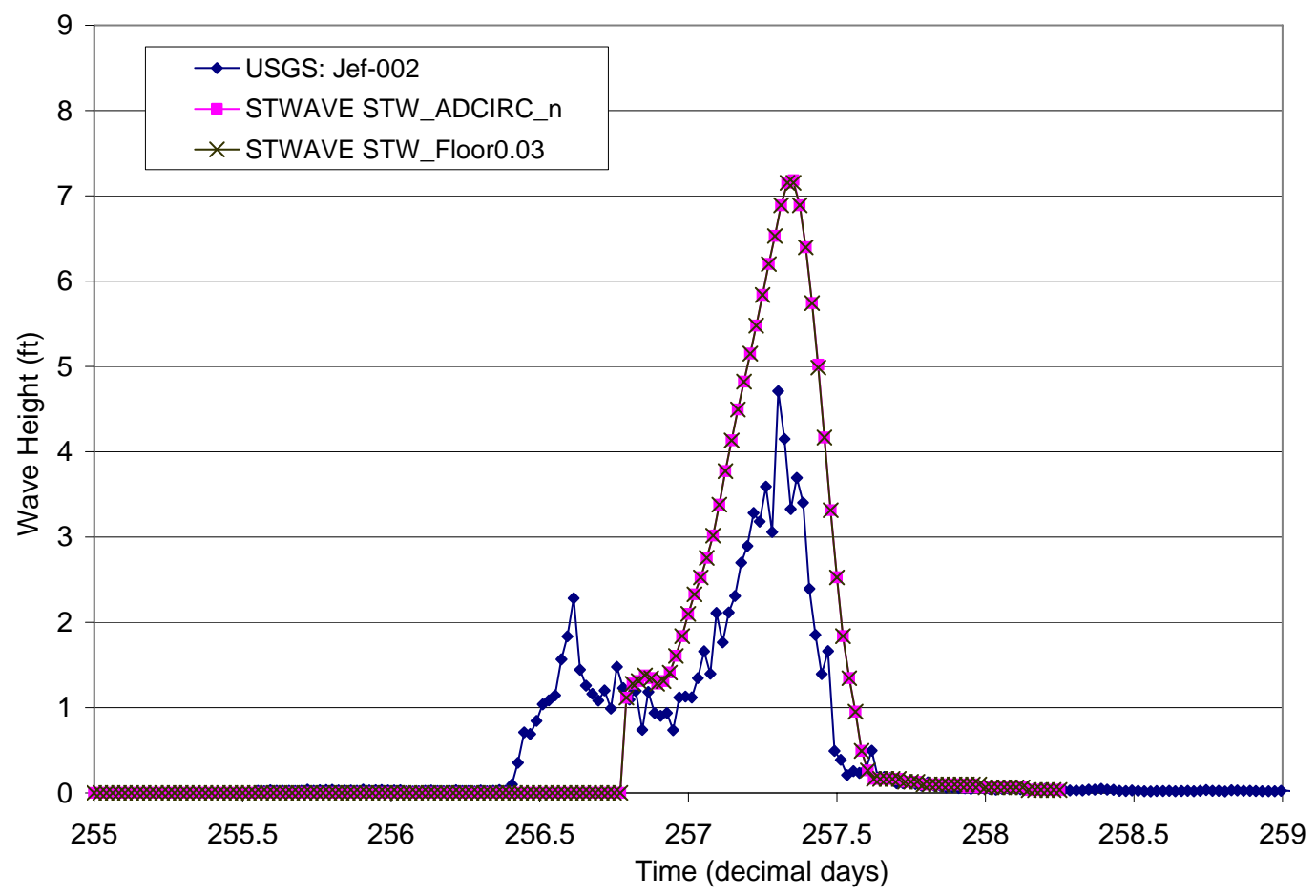

Figure 7. Time Series of STWAVE Simulated Wave Heights and Measured Waves at USGS Station Jef-002 During Hurricane Ike (2008)

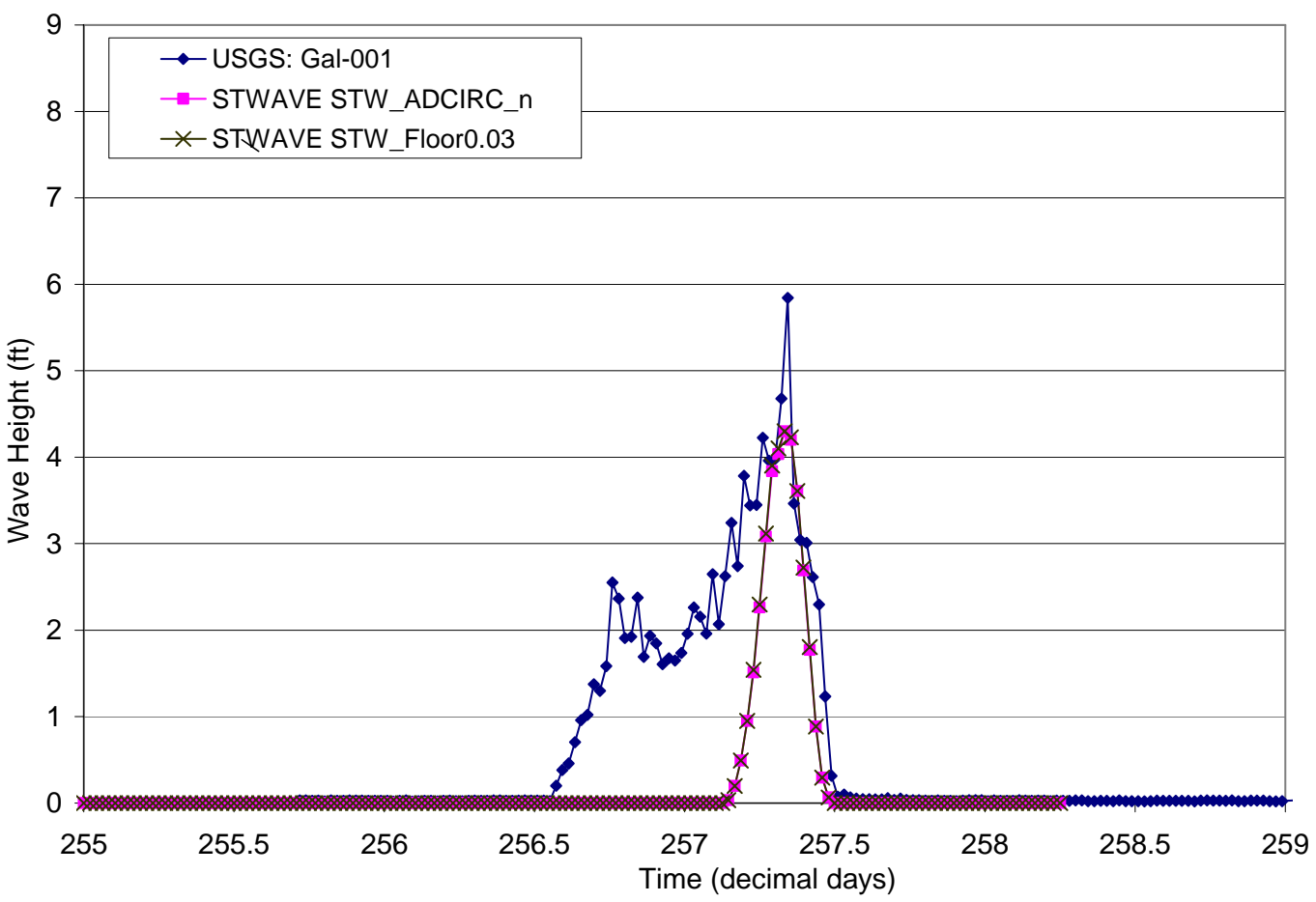

Figure 8. Time Series of STWAVE Simulated Wave Heights and Measured Waves at USGS Station Gal-001 During Hurricane Ike (2008) 


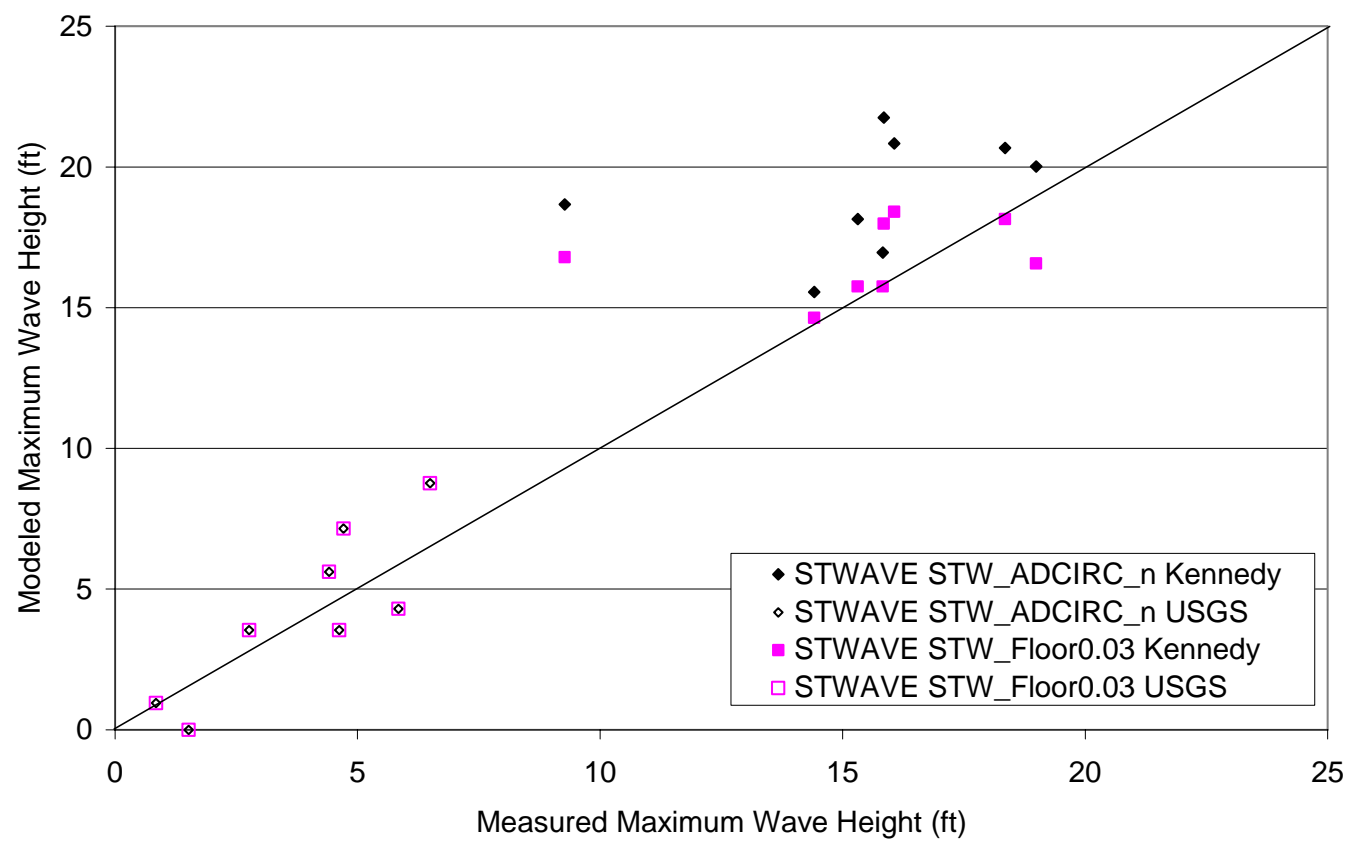

Figure 9. Scatter Plot of STWAVE simulated and Measured Waves (Kennedy and USGS Stations) During Hurricane Ike (2008)

\section{CONCLUSIONS}

This study developed STWAVE simulations of nearshore wave fields during Hurricane Ike (September 12, 2008). The STWAVE simulations apply the input offshore wave spectra from the WAM offshore wave model and surge and wind fields from the ADCIRC hydrodynamic model. The STWAVE method features five total grids with three offshore grids that cover the entire Texas coastline and two smaller nested grids that cover Galveston Bay and Corpus Christi Bay. The study applied half-plane STWAVE models for the three outer coastal grids and full-plane STWAVE models for the nested grids. Similar to the recent studies, the STWAVE bottom friction setting applies Manning's ' $n$ ' coefficients - values derived from land classification data and published literature interpolated from the ADCIRC mesh. The STWAVE models applied different bottom friction coefficients to evaluate model sensitivity to chosen parameters.

Analysis of the general STWAVE model results indicates maximum offshore wave conditions near $40 \mathrm{ft}$ at the model offshore boundary with peak periods near 16 seconds. The maximum wave conditions occur in the NE grid with smaller wave conditions in the CE and SW grids that occur well southwest of the hurricane track. Significant steepness-induced wave breaking occurs over the Texas shelf as nearshore waves nearing $25 \mathrm{ft}$ as they approach the coast. Analysis of the maximum wave height and period plots indicates the large area of inundation - simulated by ADCIRC — that occurs as the storm passes through northeast Texas. Inland areas - detailed in the NEn STWAVE grid feature wave heights up to $10 \mathrm{ft}$ in some areas with inland topography and surge levels controlling the waves.

Nearshore and inland wave data collected by Dr. Andrew Kennedy and the USGS provided measured wave parameters during the passage of the hurricane and allowed comparison of the simulated wave conditions to evaluate model performance. Comparison of the STWAVE results with the measured nearshore data indicates that a minimum Manning's ' $n$ ' bottom friction coefficient equal $0.03 \mathrm{~s} / \mathrm{m}^{0.33}$ provides the best agreement with measured nearshore data. This approach raises the open water Manning ' $\mathrm{n}$ ' value from the $0.012 \mathrm{~s} / \mathrm{m}^{0.33}$ setting applied in the ADCIRC model. The STWAVE simulations with Manning's ' $\mathrm{n}$ ' values from the ADCIRC model provide reasonable estimates of the inland wave conditions at the USGS stations. The study developed STWAVE simulations with several friction settings and values for inland areas; however, comparison of the modified inland friction results with the USGS measurements did not produce a significant improvement in model 
performance. Given the limited number of USGS inland wave measurements and the uncertainty in the measurements, a method that maintains the ADCIRC Manning's ' $n$ ' values for inland areas provides the most reasonable approach. Given this information, the STW Floor0.03 bottom friction coefficient setting — that sets the minimum Manning ' $\mathrm{n}$ ' value in the STWAVE grid to $0.03 \mathrm{~s} / \mathrm{m}^{0.33}$ - provides the best approach to date for the Hurricane Ike simulation and future TX JSS STWAVE simulations.

\section{REFERENCES}

Arcement, G.J., and V.R. Schneider. 1989. Guide for Selecting Manning's Roughness Coefficients for Natural Channels and Flood Plains, U.S. Geological Survey Water-Supply Paper 2339, U.S. Geological Survey, Denver, Colorado.

Barnes, H.H. 1967. Roughness Characteristics of Natural Channels, U.S. Geological Survey WaterSupply Paper 1849, U.S. Geological Survey, Washington D.C.

Cox, A.T., J.A. Greenwood, V.J. Cardone, and V.R. Swail, 1995. An Interactive Objective Kinematic Analysis System. Proc. Fourth International Workshop on Wave Hindcasting and Forecasting, Banff, Alberta, Canada. Available at http://www.waveworkshop.org/4thWaves/4thWaves.pdf.

Chow, V.T. 1959. Open Channel Hydraulics, McGraw-Hill Book Company, New York.

East, J.W., Turco, M.J., and Mason Jr., R.R. 2008. Monitoring Inland Storm Surge and Flooding From Hurricane Ike in Texas and Lousiana, September 2008, Open-File Report 2008-1365, United States Geological Survey. Available at: http://pubs.usgs.gov/of/2008/1365/.

Henderson, F.M. 1966. Open Channel Flow, Macmillan Publishing Company, New York.

Kennedy, A.B., Gravois, U., Zachry, B., Luettich, R., Whipple, T. Weaver, R., Reynolds-Fleming, J. Chen, Q., and Avissar, R. 2010a. "Rapidly installed temporary gauging for waves and surge, and application to Hurricane Gustav", Continental Shelf Research, doi:10.1016/j.csr.2010.07.013.

Kennedy, A.B., Rogers, S., Sallenger, A., Gravois, U., Zachry, B., Dosa, M., and Zarama, F. 2010b. "Building Destruction from Waves and Surge on the Bolivar Peninsula during Hurricane Ike," $J$. Waterway, Port, Coastal and Ocean Eng.-ASCE, doi:10.1061/(ASCE)WW.1943-5460.0000061.

Komen, G.J., Cavaleri, L., Donelan, M., Hasselmann,K., Hasselmann, S. and P.A.E.M. Janssen. 1994. Dynamics and Modelling of Ocean Waves, Cambridge University Press, 532 pp.

Luettich, R.A., and J.J. Westerink. 2004. Formulation and Numerical Implementation of the 2D/3D ADCIRC Finite Element Model Version 44.XX. Available at: http://adcirc.org/adcirc_theory_2004_12_08.pdf.

National Hurricane Center. 2010. Tropical Cyclone Report, Hurricane Ike (AL092008) 1 - 14 September, January 2009; Updated May 2010.

Powell, M.D., S.H. Houston, L.R. Amat, and N. Morisseau-Leroy, 1998. The HRD real-time hurricane wind analysis system, J. Wind Engineer. and Indust. Aerodyn, 77\&78, 53-64.

Smith, J.M., and A.R. Sherlock. (2007). Full-Plane STWAVE: II. Model Overview, Coastal and Hydraulics Engineering Technical Note CHETN I-73, U.S. Army Engineer Research and Development Center,Vicksburg, MS.

Smith, J.M., A.R. Sherlock, and D.T. Resio. 2001. STWAVE: Steady-State Spectral Wave Model User's Manual for STWAVE, Version 3.0. USACE, Engineer Research and Development Center, Technical Report ERDC/CHL SR-01-1, Vicksburg, MS. Available at: http://chl.erdc.usace.army.mil/Media/2/4/4/erdc-chl-sr-01-11.pdf.

Thompson, E. F. and V. J. Cardone. 1996. Practical modeling of hurricane surface wind fields. ASCE J. of Waterway, Port, Coastal and Ocean Engineering, 122, 4, 195-205.

United States Army Corps of Engineering (USACE). 2006. Performance Evaluation of the New Orleans and Southeast Louisiana Hurricane Protection System Draft Final Report, The Interagency Performance Evaluation Task Force (IPET); Volume IV - The Storm. 